\title{
A trial map and GIS class on junior high school with university collaboration in Yokohama, Japan
}

\author{
Toshimitsu Tabe, ${ }^{\mathrm{a}}$ Koji OHNISHI ${ }^{\mathrm{b}}$ \\ a Japan Women's University, Kawasaki City, Kanagawa Prefecture, Japan: tabe@fc.jwu.ac.jp \\ ${ }^{b}$ University of Toyama, Toyama city, Toyama Prefecture, Japan: ohnishik@hmt.u-toyama.ac.jp
}

\begin{abstract}
On the new curriculum of high school in Japan, geography will be compulsory subject in Japan from 2022. The indexes of new high school geography as compulsory subject will be 1. Using of maps and GIS, 2. Understanding of the world and International collaboration: Life and culture, issues of world, 3. Disaster prevention and ESD: natural environment and disaster, and construction of ideal society. The instruction of the GIS will be one of the issues for social studies teachers in the new curriculum. The aim of this study is to make the utilize map and GIS education content through trial class in junior high school. Trial class was done on Tsurugamine junior high school in Yokohama city with university and Yokohama city school board collaboration. In the trial class, the teacher indicated the old and new topographical maps to students and asked them to consider the characteristics of the area and the land use change. Transparent sheets overlaying is useful this activity. Transparent usage indicated the GIS function of overlay. It is good activity for students to understand the function of GIS. After the considering land use changes, they considered the future of their town. The several unused lands are spread in this area. Students present their opinions how to develop them. The important thing to carry out map and GIS class through neighborhood area is preparation of adequate maps. For this preparation, collaboration with university geography stuffs or undergraduate students are effective.
\end{abstract}

Keywords: High school Geography, Map education, GIS, Transparent sheet, neighborhood learning

\section{Introduction}

New national curriculum of high school will be carried out from 2022 in Japan. Geography as high school subject has been almost selective subject since 1947. The number of students who take geography in high school has started to decrease since around 1980. In new curriculum, geography will be compulsory subject in Japan. It is the result of geography teachers' and academic geographers' desires and efforts. The coherent geography education curriculum from elementary school to the high school will be build up. Index of high school geography as compulsory subject will be following; 1. Using of maps and GIS, 2. Understanding of the world and International collaboration: Life and culture, issues of world, 3. Disaster prevention and ESD: natural environment and disaster, and construction of ideal society.

The number of Geography teachers is not enough. From 2022, high school geography will be taught not only geography teachers, but also history teachers. Many history teachers worry about maps and GIS content of new geography subject. They think GIS is very difficult content. The instruction of the GIS will be one of the issues in the new curriculum. It is important for history teachers to understand geography concept through teaching GIS with fun (Ida, 2016). We need understandable GIS and map education contents.

The aim of this study is to make the utilize map and GIS education content through trial class in middle school. Trial class was done on Tsurugamine junior high school in Yokohama city (Fig.1).

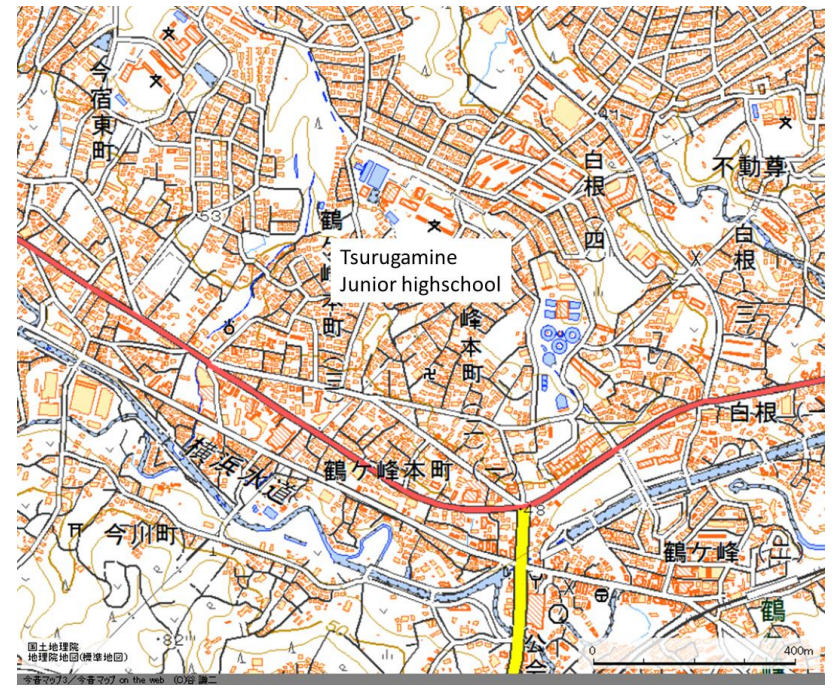

Fig.1 Location of Tsurugamine junior high school (Source: GSI Map)

\section{Preparation of the trial class}

For the trial class, the teacher was supported by Yokohama city school board and Japan women's university geography staffs. The teacher and university staffs were discussed the content of the trial class. The theme of the trial class was neighborhood learning. Several materials were needed to carry out the class. The teacher needed the regional statics around the school and topographical maps.

University geography staffs and university students prepared the materials. Statics is important for students to 
understand the situation of the school district. Maps are also important. They tried to create the connection between map education and GIS education with transparent sheets. They printed the maps on the transparent sheets for learning the overlay function of GIS.

They determined the role of the trial class. The trial class had two periods. The first period was carried out by the junior high school teacher. On the first period, the theme of the class was the characteristics of the town. Students used the statics and maps. The second period theme was "How to develop their town?" Students use old and new topographical maps.

\section{Trial classes}

The trial classes were done on 22nd and 26th Feb. 2016. In this chapter, we describe the activities of trial classes. The theme of the trial class was "survey our neighborhood".

\subsection{The first period}

In the first period, the teacher indicated the new topographical maps to students and asked them to consider the characteristics of the area (Fig.2). At first, they share the map information on the black board. The wide printed map was around the junior high school. After the activity, the same topographical map was distributed to students. Teacher made the instruction for students to paint the main roads and railways with yellow pens.

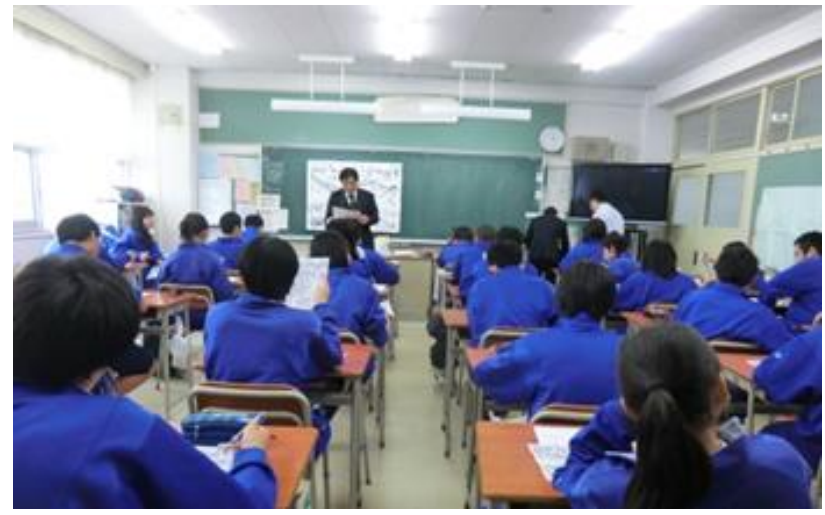

Fig.2 First period of the trial class

Next work is painting the buildup area with red, farm field with yellow green and trees with green. After the painting, they describe their own findings on the worksheets through painting (Fig.3).

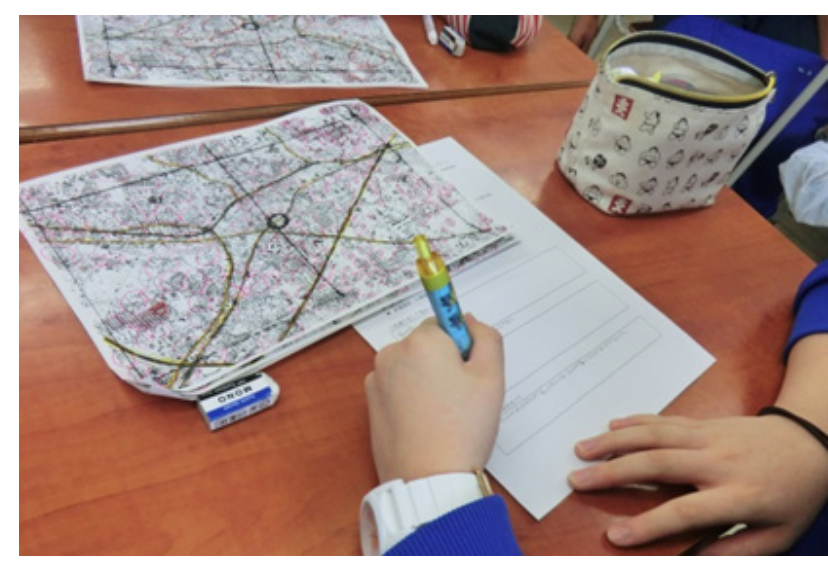

Fig. 3 Describing the findings on the worksheet

After painting the map, transparent sheets were distributed to students. Three of the sheets made a set. On the transparent sheets were printed topographical maps on 1932, 1967 and present. They compared the new and old maps (Fig.4).

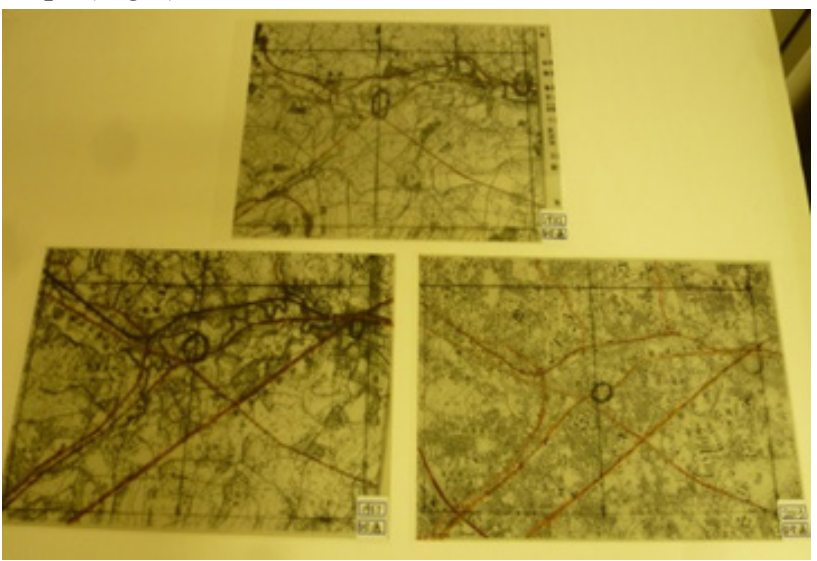

Fig.4 a set of transparent sheets

Next work was painting the topographical map in 1967. It was the same way with present map. After painting, teacher made the instruction for students to pay attention to the land use change and no change. Students got clear focus on two maps comparison (Fig. 5). During the working, many students make reference the transparent sheets.

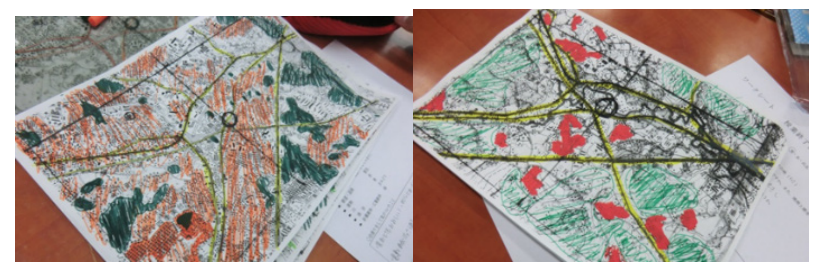

Fig.5 Comparison old and new topographical maps: left is present and right is 1967.

\subsection{Second period}

In the second period, students considered the regional changes with comparing the topographical map in 1932 to in 1967 (Fig.6), present and they made presentation the land use change (Fig.7). Teacher asked them to find changing and not changing land use. Transparent sheets 
overlaying is useful this activity. Transparent usage indicated the GIS function of overlay. It is good activity for students to understand the function of GIS.
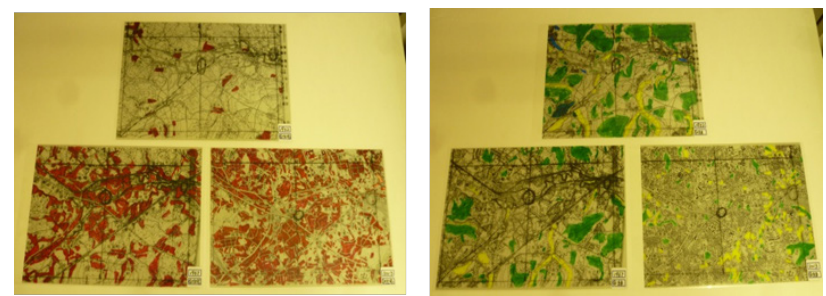

Fig. 6 Comparison old and new topographical maps: red is buildup area and green is trees and farm field

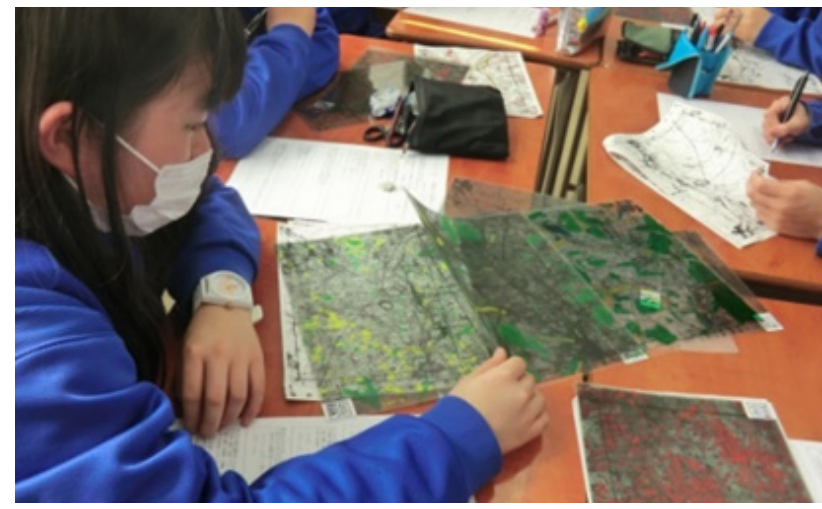

Fig.7 Trying to find the change of land use

After the considering past changes, they considered the future of their town. The unused lands are spread in this ar-ea. Students present their opinions how to develop them. They had to plan the future landscape of their town. For this activity, they understood the present data and prediction data were needed for planning. They also needed the vision for future town that they want to create.

\section{Conclusions}

The important thing to carry out map and GIS class through neighborhood area is preparation of adequate maps. For this preparation, collaboration with university geography stuffs or undergraduate students are inevitable in several years. After the accumulation these experiences, school teachers will be able to prepare these materials.

Many teachers feel GIS has difficult functions to teach. But the function is not so complex. Adequate maps and adequate instruction will make the geography class understandable.

\section{Acknowledgements}

We are grateful to Mr. Kuroki for trial classes in Tsurugamine junior high school

\section{References}

Ida, Y. (2016): New high school geography and future geography education in Japan. Jinbun chiri,(Human geography), 68(1), 66-78 (Japanese). 